\title{
Neutrophil/Lymphocyte Ratios, Platelet/Lymphocyte Ratios, and Mean Platelet Volume Values in Patients with Measles
}

\author{
Abdullah Solmaz ${ }^{1}$, Abit Demir ${ }^{1}$, Hüseyin Gümüş ${ }^{1}$, Mustafa Aksoy ${ }^{2}$, Filiz Solmaz ${ }^{1}$ \\ 1. Pediatrics, Harran University, Şanlıurfa, TUR 2. Dermatology, Harran University, Şanlıurfa, TUR
}

Corresponding author: Abdullah Solmaz,dr.solmaz@hotmail.com

\begin{abstract}
Aim: The purpose of this study was to compare neutrophil/lymphocyte ratio (NLR), platelet/lymphocyte ratio (PLR), and mean platelet volume (MPV) values of patients with measles within the healthy control group and then determine the utility of these parameters for determination of inflammatory situation in patients with measles.
\end{abstract}

Materials and method: A total of 51 pediatric patients who had visited Harran University Medical Faculty Pediatrics Clinic between June 2018 and May 2019 and who had been diagnosed with measles after anamnesis, clinical, and serological evaluations were included our study; 49 healthy children who visited our clinic for various reasons and had taken hemogram tests were also added to our study as the control group.

Results: NLR and PLR values were observed higher than the control group for patients diagnosed with measles; however, the difference between the two groups was not statistically significant ( $p$ values 0.515 and 0.796, respectively). When MPV values of patients diagnosed with measles and control groups were compared, it was determined that MPV value was statistically lower in patients diagnosed with measles (p: 0.001).

Conclusion: Based on the parameters obtained through our study, it can be said that NLR and PLR are not suitable parameters for proving inflammation in patients with measles but MPV can be used as a convenient parameter for that purpose. However, prospective studies conducted with more patients are needed in this respect.

Categories: Dermatology, Pediatrics, Infectious Disease

Keywords: measles, neutrophil/lymphocyte ratios, platelet/lymphocyte ratios, mean platelet volume

\section{Introduction}

Received 01/02/2020

Review began 01/05/2020

Review ended 01/06/2020

Published 01/09/2020

(c) Copyright 2020

Solmaz et al. This is an open access

article distributed under the terms of the Creative Commons Attribution License CC-BY 3.0., which permits unrestricted use, distribution, and reproduction in any medium, provided the original author and source are credited.
Measles is particularly seen during childhood; it is an epidemic and a highly contagious infectious disease. Its agent is the rubeola virus which is a part of the Paramyxoviridae family. The spread of the disease occurs as a result of aerosol-form parts of the respiratory secretions of patients reaching the sensitive host. For the infection of measles, both antibody response and cellular response is important [1-4]. Hematological side effects such as leucopenia, lymphopenia, and thrombocytopenia are observed to be connected with measles infection [5-6].

Even though various identifiers have been defined for many diseases during the recent years, the determination of these identifiers takes time and is costly. Peripheral blood cells display quantitative and functional changes as a response to the inflammation evolving in the body [7]. Based on these changes, a series of inflammatory biological identifiers like neutrophil/lymphocyte ratio (NLR), platelet/lymphocyte ratio (PLR), and mean platelet volume (MPV), which could be easily obtained through peripheral blood count in infectious or inflammatory diseases, were examined [8-10].

There is no such study in the literature that evaluates the inflammatory parameters like NLR, PLR, and MPV in patients with measles. The purpose for this study is to compare the NLR, PLR, and MPV values of patients with measles within the healthy control group and then determine the utility of these parameters for the determination of inflammatory situations in patients with measles.

\section{Materials And Methods}

A total of 51 pediatric patients who had visited Harran University Medical Faculty Pediatrics Clinic between June 2018 and May 2019 and who had been diagnosed with measles after anamnesis, clinical, and serological evaluations were included our study; 49 healthy children who visited our clinic for various reasons and had taken hemogram tests were also added to our study as the control group; they did not have any viral, bacterial, and fungal infection, systemic inflammatory disease or malignancy in any organs. 
The gender, age, neutrophil count, lymphocyte count, leucocyte count, platelet count, NLR, PLR, and MPV values of the patients and the control group were retrospectively scanned and recorded. NLR was calculated by dividing the neutrophil count by the lymphocyte count and PLR was calculated by dividing the platelet count by the lymphocyte count. The complete blood count (CBT) was calculated through the optical scatter laser method (Cell-Dyn 3700, Abbott Diagnostics, Chicago, USA).

The exclusion criteria for the study were determined as any thyroid disease, cardiovascular disease, hypertension, hypercholesterolemia, systemic diseases like diabetes mellitus, malignancy in any organs, or existence of a local or systemic infection.

Data distributed check was conducted using the Shapiro-Wilk test. Since the data distribution was normal, the student t-test was used for the comparison of the two groups. Identifying statistics for continuous variables are shown as mean and standard deviation values. For the analysis of genders, the Pearson chisquare was used. Statistical analysis was performed using the Statistical Package for the Social Sciences; version 21 (SPSS Inc., Chicago, IL) program; p<0.05 was accepted as statistically significant.

\section{Results}

For our study, any statistically significant difference was not detected in terms of gender and age ratio between patients diagnosed with measles (26 males, 25 females; mean \pm sd age $5.42 \pm 2.31$ ) and the healthy control group (26 males, 23 females; mean \pm sd age $5.41 \pm 3.41)(\mathrm{p}>0.05)$.

The neutrophil count of the patients diagnosed with measles was found as $4.31 \pm 2.83 \times 103$ and the neutrophil count of the healthy control group was determined as $5.87 \pm 2.41 \times 103$, and the difference between two groups was statistically significant (p:0.001).

The lymphocyte count of the patients diagnosed with measles was found as $3.27 \pm 2.34 \times 103$ and the lymphocyte count of the healthy control group was determined as $3.28 \pm 1.01 \times 103$, and the difference between two groups was not statistically significant (p:0.339).

The leukocyte count of the patients diagnosed with measles was found as $8.57 \pm 4.31 \mathrm{x} 103$ and the leukocyte count of the healthy control group was determined as $10.17 \pm 3.08 \times 103$, and the difference between two groups was statistically significant (p:0.005).

The platelet count of the patients diagnosed with measles was found as $325.25 \pm 158.31 \times 103$ and the platelet count of the healthy control group was determined as $384.96 \pm 110.65 \times 103$, and the difference between two groups was statistically significant (p:0.002).

The NLR value of the patients diagnosed with measles was found as $2.41 \pm 2.43$ and the NLR value of the healthy control group was determined as $1.94 \pm 0.86$, and the difference between the two groups was not statistically significant (p: 0.515).

The PLR value of the patients diagnosed with measles was found as $167.57 \pm 145.58$ and the PLR value of the healthy control group was determined as $124.43 \pm 30.16$, and the difference between two groups was not statistically significant (p:0.796).

The MPV value of the patients diagnosed with measles was found as $6.42 \pm 1.38$ and the MPV value of the healthy control group was determined as $7.03 \pm 0.92$, and the difference between the two groups was statistically significant (p:0.001).

The laboratory results of the patients diagnosed with measles and the control group are presented in Table 1 . 


\section{Cureus}

\begin{tabular}{|c|c|c|c|}
\hline Parameters & Measles (n:51)(Mean \pm SD) & Healthy control (n:49)(Mean \pm SD) & $P$ value \\
\hline Number of neutrophils $\left(x 10^{3} / \mathrm{ml}\right)$ & $4.31 \pm 2.83$ & $5.87 \pm 2.41$ & 0.001 \\
\hline Number of lymphocyte (x103/ml) & $3.27 \pm 2.34$ & $3.28 \pm 1.01$ & 0.339 \\
\hline Number of leukocyte (x103/ml) & $8.57 \pm 4.31$ & $10.17 \pm 3.08$ & 0.005 \\
\hline Number of platelet $\left(\times 10^{3} / \mathrm{ml}\right)$ & $325.25 \pm 158.31$ & $384.96 \pm 110.65$ & 0.002 \\
\hline NLR & $2.41 \pm 2.43$ & $1.94 \pm 0.86$ & 0.515 \\
\hline PLR & $167.57 \pm 145.58$ & $124.43 \pm 30.16$ & 0.796 \\
\hline MPV & $6.42 \pm 1.38$ & $7.03 \pm 0.92$ & 0.001 \\
\hline
\end{tabular}

\section{TABLE 1: Laboratory findings of patients with measles and the healthy control group}

\section{Discussion}

During the incubation period, the measles virus settles in the regional lymphoid tissues. The first viremia occurs in the reticuloendothelial system and the second viremia occurs at the body surface. Viral distribution starts with prodromal symptoms. Once the antibody production starts along with rashes, then viral distribution and symptoms decrease simultaneously. Immune system suppression occurs through the suppression of Th1 cells by infecting $\mathrm{CD} 4+\mathrm{T}$ cells. The studies conducted during the recent years have shown that the measles virus uses nectin- 4 receptors in the respiratory tract epitheliums by targeting alveoli macrophages, dendritic cells, and lymphocytes; for other tissues, it uses CD150 receptors on which the measles virus performs lymphocyte stimulation [11-14].

The disease is first defined with clinical findings; the presence of lymphopenia supports the findings. If the measles is not epidemic, the disease is diagnosed clinically. Serologically, it is expected that the measles IgM levels start to increase from day one or two of the disease up to the end of a month. However, if the measles IgM, which is taken during the first 72 hours of the disease, is negative, it might need to be repeated two-four weeks after the acute disease sets in. Four times or more increase in IgG level indicates the diagnosis. Production of the virus through culturing blood, urine, and respiratory tract samples and proving the virus itself or viral ribonucleic acid with polymerase chain reaction (PCR) technique is possible [15-17].

The white blood cells are the main cells of inflammation and play a role in the pathogenesis of many diseases. An increase in neutrophil counts during the acute inflammatory processes, along with decrease in lymphocyte counts based on acute stress, reflects the changes in the immune system. Existence of leucocytosis is interpreted in support of inflammation or infection [18-20]. In recent years, a value that includes both increasing neutrophil counts during the acute inflammation and the decreasing lymphocyte count during acute stress has been utilized. This value is called as NLR and its popularity is increasing day by day. NLR value is generally accepted as the indication of subclinical inflammation and it has been observed that this value increases during many infectious and inflammatory diseases [10,21-22].

The evolution of leucopenia in 12 patients has been observed during the study conducted by Karakecili et al. with 28 adult patients with measles [5]. Another study evaluating adult patients with measles conducted by Sunnetcioglu et al. has observed leucopenia in 7 (14\%) patients [6]. Leucopenia evolving following the measles infection is accepted as secondary in bone marrow suppression and is related to apoptosis in noninfected cells [13]. There is no such study in the literature that evaluates NLR parameters in patients with measles. In our study, NLR values of patients with measles was higher than the control group, and the difference between the two groups was not statistically significant.

Platelets are blood cells that play a role in coagulation. In case of any bleeding, the immediately reach that affected area and try to stop the bleeding by sticking to each other and constricting the vein. As being a part of the natural immune system, platelets could be increased as a response to "acute phase reaction" during the inflammation process. This increase in platelets may reflect the activity of bone marrow cells as a response to inflammatory phase interleukins such as IL-1 and Il-6 [23-24]. Large platelets are metabolically more active. MPV is the most commonly used measurement of platelet size and is accepted as in-vivo sign of the reactivity of platelets $[9,25]$.

Thompson et al. have determined the relation between the MPV and platelet aggregation, positive correlation between ATP in platelets and $\beta$ thromboglobulin content and that ATP and $\beta$ thromboglobulin 
secretion progressively increases along with the increase in mean platelet volume after the stimulation [25]. Consequently, MPV alone could be accepted as an indicator of platelet activation [26]. Many studies taken place in the literature have reported the relation between MPV and many inflammatory and infectious diseases $[9,27]$.

Thrombocytopenia was observed in 26 (52\%) patients in the study conducted by Sunnetcioglu et al. with 50 adult patients with measles [6]. However, as far as we know, there is no such study in the literature that evaluates MPV parameters in patients with measles. In our study, the MPV values of patients with measles were lower than the control group, and the difference between two groups was statistically significant.

In recent years, it has been proved that the PLR value, obtained through dividing platelet count to lymphocyte count, has an important effect on systemic inflammatory response pathogenesis and can be used as an inflammation indicator $[8,28]$. Many studies in the literature have reported the relation between PLR (as well as MPV) and many inflammatory and infectious diseases [9,29-30]. Even though thrombocytopenia is observed in patients with measles, there is no such study in the literature that evaluates PLR levels in patients with measles. In our study, PLR values of patients with measles were higher than the control group, and the difference between the two groups was not statistically significant.

\section{Conclusions}

Based on the data obtained through our study, it has been concluded that NLR and PLR are not suitable parameters for proving inflammation in patients with measles, but MPV is an appropriate parameter in terms of proving the inflammation in patients with measles. However, prospective studies conducted with more patients are needed in this respect.

\section{Additional Information \\ Disclosures}

Human subjects: Consent was obtained by all participants in this study. Animal subjects: All authors have confirmed that this study did not involve animal subjects or tissue. Conflicts of interest: In compliance with the ICMJE uniform disclosure form, all authors declare the following: Payment/services info: All authors have declared that no financial support was received from any organization for the submitted work. Financial relationships: All authors have declared that they have no financial relationships at present or within the previous three years with any organizations that might have an interest in the submitted work. Other relationships: All authors have declared that there are no other relationships or activities that could appear to have influenced the submitted work.

\section{References}

1. Asaria P, MacMahon E: Measles in the United Kingdom: can we eradicate it by 2010 . Br Med J. 2006, 333:890.10.1136/bmi.38989.445845.7C

2. Willke TA, Söyletir G, Doganay M: Infectious Diseases and Microbiology. Nobel Tip Publication, Istanbul; 2008.

3. Pahsa A, Özsoy MF, Altunay H, et al.: Adult measles: retrospective evaluation of 284 cases . Flora. 1999, 4:200-5.

4. Muscat M, Bang H, Glismann S: Measles is still a cause for concern in . Europe. Euro Surveill. 2008, 13:18837.

5. Karakeçili F, Akın H, Çıkman A, Özçiçek F, Kalkan A: Measles outbreak in the adult age group: evaluation of 28 cases. Mikrobiyol Bul. 2016, 112-21. 10.5578/mb.10692

6. Sunnetcioglu M, Baran AI, Sunnetcioglu A, Mentes O, Karadas S, Aypak A: Clinical and laboratory features of adult measles cases detected in Van, Turkey. J Pak Med Assoc. 2015, 65:273.

7. Grivennikov SI, Greten FR, Karin M: Immunity, inflammation, and cancer. Cell. 2010, 140:883-99. 10.1016/j.cell.2010.01.025

8. An I, Ucmak D: Evaluation of neutrophil-to-lymphocyte ratio, platelet-to-lymphocyte ratio, mean platelet volume, and C-reactive protein in patients with psoriasis vulgaris. Dicle Med J. 2018, 3:327-34

9. An I, Ucmak D, Ozturk M: Evaluation of neutrophil-to-lymphocyte ratio, platelet-tolymphocyte ratio and mean platelet volume in patients with lichen planus. Ann Med Res. 2019, 26:161-4.

10. An I, Ucmak D,Ozturk M, Aksoy M, Yildiz I, Ucan E: Neutrophil/Iymphocyte ratio, platelet/Iymphocyte ratio, mean platelet volume and C-reactive protein values in psoriatic arthritis patients. Ann Med Res. 2019, 26:894-8. 10.5455/annalsmedres.2019.02.074

11. Mason RS: Measles. Nelson Textbook of Pediatrics, 19th Edition. Kliegman RM, Stanton BF, St Geme III JW, Schor NF, Behrman RE (ed): Elsevier Saunders, Philadelphia; 2011. 1073-1075.

12. Mason WH: Measles. Nelson Textbook of Pediatrics, 19th Edition. Kliegman RM, Stanton BF, St Geme III JW, Schor NF (ed): Elsevier Saunders, Philadelphia; 2016. 1542- 1548

13. Okada H, Kobune F, Sato TA, et al.: Extensive lymphopenia due to apoptosis of uninfected lymphocytes in acute measles patients. Arch Virol. 2000, 145:905-20. 10.1007/s007050050683

14. Dales LG, Kizer KW, Rutherford GW, Pertowski CA, Waterman SH, Woodford G: Measles epidemic from failure to immunize. West J Med. 1993, 159:455-64.

15. Pickering LK, Baker CJ, Kimberlin DW, Long SS: Measles. Red Book: 2012 report of the Committee on Infectious Disease. American Academy of Pediatrics, Elk Grove Village, IL; 2012. 489-499.

16. Wong RD, Goetz MB, Mathisen G, Henry D: Clinical and laboratory features ofmeasles in hospitalized adults . Am J Med. 1993, 95:377-83. 10.1016/0002-9343(93)90306-A 
17. Giladi M, Schulman A, Kedem R, Danon YL: Measles in adults: a prospective study of 291 consecutive cases . Br Med J. 1987, 295:1314. 10.1136/bmj.295.6609.1314

18. Jilma B, Blann A, Pernerstorfer T, et al.: Regulation of adhesion molecules during human endotoxemia. Am J Respir Crit Care Med. 1999, 3:857-863. 10.1164/ajrccm.159.3.9805087

19. O'Mahony J, Palder S, Wood J, McIrvine A, Rodrick M, Demling R, Mannick J: Depression of cellular immunity after multiple trauma in the absence of sepsis. J Trauma. 1984, 24:869-875.

20. Kolaczkowska E, Kubes P: Neutrophil recruitment and function in health and inflammation . Nat Rev Immunol. 2013, 13:159-75. 10.1038/nri3399

21. Zahorec R: Ratio of neutrophil to lymphocyte counts-rapid and simple parameter of systemic inflammation and stress in critically ill. Bratisl Lek Listy. 2001, 102:5-14. 10.4149/BLL_2014_076

22. Duffy BK, Gurm HS, Rajagopal V, Gupta R, Ellis SG, Bhatt DL: Usefulness of an elevated neutrophil to lymphocyte ratio in predicting long-term mortality after percutaneous coronary intervention. Am J Cardiol. 2006, 97:993-6. 10.1016/j.amjcard.2005.10.034

23. Zareifar S, Farahmand Far MR, Golfeshan F, Cohan N: Changes in platelet count and mean platelet volume during infectious and inflammatory disease and their correlation with ESR and CRP. J Clin Lab Anal. 2014, 28:245-48. 10.1002/jcla.21673

24. Unsal E, Aksaray S,Koksal D, Sipit T: Potential role of interleukin-6 in reactive thrombocytosis and acute phase response in pulmonary tuberculosis. Postgrad Med J. 2005, 81:604-607. 10.1136/pgmj.2004.030544

25. Thompson CB, Jakubowski JA, Quinn PG, Deykin D, Valeri CR: Platelet size as a determinant of platelet function. J Lab Clin Med. 1983, 101:205-13.

26. Cox D: Methods for monitoring trombosit function. Am Heart J. 1998, 135:160-169. 10.1016/s00028703(98)70244-3

27. Endler G, Klimesch A, Sunder-Plassmann H, et al.: Mean platelet volume is an independent risk factor for myocardial infarction but not for coronary artery disease. Br J Haematol. 2002, 117:399-404. 10.1046/j.13652141.2002.03441.x

28. Yılmaz U, Ozdemir O, Batum O, Ermin S: The prognostic role of neutrophil-lymphocyte ratio and plateletlymphocyte ratio in patients with stage III non-small cell lung cancer treated with concurrent chemoradiotherapy. Indian J Cancer. 2018, 55:276-281. 10.4103/ijc.IJC_624_17

29. Kostrubiec M, Łabyk A, Pedowska-Włoszek J, et al.: Mean platelet volume predicts early death in acute pulmonary embolism. Heart. 2010, 96:460-5.

30. Asahina A, Kubo N, Umezawa Y, Honda H, Yanaba K, Nakagawa H: Neutrophil-lymphocyte ratio, plateletlymphocyte ratio and mean platelet volume in Japanese patients with psoriasis and psoriatic arthritis: response to therapy with biologics. J Dermatol. 2017, 44:1112-21. 10.1111/1346-8138.13875 